\title{
Mothers' Perceived Vulnerability, Perceived Threat, and Intention to Administer Preventive Medication to Their Children
}

\author{
Phuong Nguyen \\ ESCP Europe Business School \\ E-Mail: pnguyen@escpeurope.eu
}

\begin{abstract}
The present research addressed whether mothers' perception that their children are vulnerable to and threatened by a certain health problem increases their intention to use over-the-counter (OTC) medications to prevent it. The research aimed to examine the predictive validity and the moderating effects of perceived vulnerability and perceived threat on mothers' intention to administer over-the-counter preventive medications to their school-aged children. Derived from social cognition models, a causal model was developed and tested with data collected from 299 mothers in Ho Chi Minh City, Vietnam, regarding the vitamin supplement category. The model was found to significantly predict mothers' intention to use OTC medications. Perceived vulnerability and perceived threat did not predict intention but moderated the relationship between perceived benefit and intention to administer vitamin supplements. Theoretical and managerial implications and limitations of the research are also discussed.
\end{abstract}

Keywords: Intention, Perceived vulnerability, Perceived threat, Vitamin supplement

\section{INTRODUCTION}

Children's medications can be used for either the treatment or the prevention of a possible illness. Preventive medications can be used either to prevent infectious diseases from happening or to enhance children's general health and immunity. Medicating children with over-the-counter (OTC) preventive pharmaceutical products is part of parents' consuming behavior and becomes more important when the logic of medicating shifts from medical professionals' to consumers' choices (Moorman \& Erika, 1993). 
Consumers use pharmaceutical products differently than they do other products because consumers' health behavior has unique characteristics. Medicating intention and behavior toward pharmaceutical products marketed by pharmaceutical firms are key constructs used in both academic research and professional market surveys to explain and to predict consumption of pharmaceutical products. Further, within the context of children's preventive medication, a perceived health threat is important to research because of its theoretical interest, its managerial relevance, the significance of its contribution to the welfare of children, and public policy implications (Menon, Raghubir, \& Agrawal, 2008).

Although behavioral intention has been intensively studied within the domain of consumer behavior and marketing, medicating intention with regard to pharmaceutical products has not received much attention from academic researchers. Intention to administer OTC medication to children has been largely ignored in marketing academic research, and little work on it has ever been conducted and published. Thus, the questions regarding parents' perceptions, beliefs, and behaviors toward administering OTC preventive medications to their children remain. The present research aims to test the predictive validity and/or the moderating effects of perceived vulnerability and perceived threat within the prediction model of intention.

This issue should be of high interest to marketing academics in the field of pharmaceutical marketing because such research would help them understand patient behaviors and consequently would enhance performance of life science firms and would improve patient welfare (Manchanda et al., 2005; Stremersch \& Van Dyck, 2009).

\section{THEORETICAL BACKGROUND AND HYPOTHESES}

\section{Medical Prevention}

Children's OTC medications can be used as prevention from a possible illness. Preventive medications can be administered to children who do not yet have or who have just developed a health problem, that is, in an early stage without symptoms. Thus, they can be used for primary and secondary prevention (Clark \& MacMahon, 1967). As depicted in Figure 1 (Kuehlein, Sghedoni, Visentin, Gérvas, \& Jamoulle, 2009), primary and secondary prevention types, as perceived by parents, occur in the absence of illnesses. On the other hand, quaternary and tertiary preventions occur when parents perceive the presence of an illness regardless of the actual diagnosis (Jamoulle \& Roland, 2003). 
To study preventive medicating behaviors within the domain of consumer health behavior, one needs to observe parents' perceptions as they shift from the left upper and lower quadrants to the right ones, as illustrated in Figure 1. Unlike the shift from the nonexistence to the existence of a disease supported by medical diagnosis, the shift from the absence to the presence of an illness, as perceived by consumers, is a continuous variable. Thus, measures of parents' perceptions of the existence of illnesses are considered on a continuum.

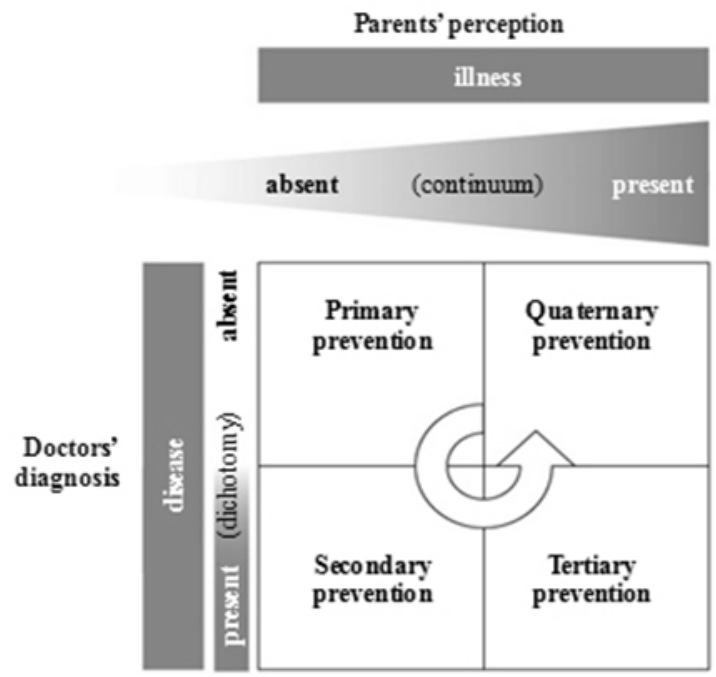

Figure 1 Conceptualization of Medical Prevention

(Adapted from Kuehlein et al., 2009)

The point to be made is that parents will not have a strong intention to prevent certain health problems in their children until the presence of an illness becomes more obvious, when it shifts from the left half to the right half of the quadrangular in Figure 1. Further, in light of health belief model (Becker et al., 1977) and theory of protection motivation (Rogers, 1983), such a shift in parents' perception depends on their perceptions if their children's vulnerability to and/or perceived severity of a certain illness. Perceived vulnerability is the perceived likelihood of contracting an illness. Perceived severity is the perceived seriousness of the consequences of the illness. Theoretically, parents seem to be concerned more with the vulnerability to an illness rather than its severity. On the contrary, parents appear to worry about the severity of the illness only if they perceive a certain level of vulnerability. Therefore, it is reasonable to assume that parents' intention to administer preventive medications to their children increases with the higherperceived vulnerability and the higher interaction between perceived vulnerability and perceived severity. 


\section{OTC Medicating Intention}

Among pharmaceutical products, OTC medications differ from prescription ones because they allow end-users to evaluate and to decide on the use of the medications. Generally, OTC medications are effective drugs with established safety profiles that consumers, adults, and children may use to treat common, simple health problems. This class of medications can be obtained from retail pharmacies without much effort and without medical consultation. The use of OTC medications depends primarily on the willingness of consumers and thereby is more relevant for studies with social cognition models. Regarding OTC children's medications, parents or caregivers make decisions to administer the medications to their children.

Medicating behaviors are distinctive health behaviors that have significant effects on individuals' health and, to a certain extent, are under individuals' control (Conner $\&$ Norman, 2005). A number of cognitive factors from social cognition models are intensively applied as a conceptual framework in health behavior research to explain and/or to predict medicating intention and behavior. Intention models are highly relevant in research of new products and services, new consumer segments, repeated consumers, consumption levels, and consumer loyalty of available products and services in the marketplace. The intensity of behavioral intention to use a product or service can be measured by consumers' subjective probability to use such a product or service (Fishbein \& Ajzen, 1975).

\section{Models of Intention}

As intentions are assumed to predict behaviors, most contemporary theories of human social behaviors utilize intention as an important variable. These theories examine factors that lead to the formation of intentions (Fishbein \& Ajzen, 1975). The most widely used social cognition models in research of health behavior are the health belief model (Becker et al., 1977), the theory of protection motivation (Rogers, 1983), the theory of reasoned action (Fishbein \& Ajzen, 1975), the theory of planned behavior (Ajzen, 1991, 2012), and the reasoned action model (Fishbein \& Ajzen, 2010). In general, these models explain that the desirability of a human behavior depends on individuals' cognitive factors' being summed products of the expectancy and value of specific outcomes (Conner \& Norman, 2005).

The health belief model (Becker et al., 1977) was developed in the 1950s to explain people's failure to participate in preventive health behaviors. The basic concept is that people's behaviors depend on their individual values and judgments about the goals that a particular action will achieve. The common goal is to avoid a health problem or a disease based on the subject's feelings about susceptibility and 
severity of the health problem along with perceived threats, benefits, and obstacles associated with a preventive action. In the health belief model, the independent variables are perceived threat, which depends on perceived susceptibility to and severity of an outcome behavior; perceived advantages and disadvantages; perceived barriers; and cues to action. These variables predict the likelihood of one's action against the preventive action. However, there is a lack of evidence from empirical studies on how the two constructs of perceived susceptibility and perceived seriousness combine to predict the likelihood of taking preventive health actions. The issue is whether susceptibility and severity should be combined additively or multiplicatively as per the expectancy value structure that the health belief model suggests (Conner \& Norman, 2005). Theoretically, perceived vulnerability and the interaction term of perceived vulnerability and severity predict the behavioral intention to take preventive health actions.

Rogers (1975) proposed the theory of protection motivation and later revised the model to provide a conceptual model of fear appeals focusing on cognitive medicating processes. The theory of protection motivation details adaptive and maladaptive responses to a health threat by means of threat appraisal and coping appraisal. Threat appraisal is conceptually computed by perceived vulnerability and perceived severity of the health threat. Factors that might increase the probability of maladaptive response include both intrinsic and extrinsic rewards, such as satisfaction, bodily pleasure (intrinsic), and social approval (extrinsic) (Rogers, 1983). Coping appraisal concerns the evaluation of behavioral alternatives that are likely to minimize the health threat. This process is said to be dependent on one's expectancy to take the action that can remove the health threat (response efficacy) and a belief in one's capability to implement the recommended behavior (self-efficacy) (Conner \& Norman, 2005).

Fishbein and Ajzen (1975) first developed the theory of reasoned action in the 1970s and later extended the theory to become the theory of planned behavior (Ajzen, 1991, 2012). According to the theory, the attitude toward the behavior develops based on the evaluation of the likely consequences of a given behavior. Subjective norm deals with the likelihood of approval or disapproval of a behavior by the subject's friends, relatives, professional people, public media, and the like. Perceived behavioral control deals with the presence or absence of factors that make the behavior easier or more difficult to perform. Fishbein and Ajzen (2010) called the later version of the theory the reasoned action model. Recently, two additional cognitive factors, perceived susceptibility and perceived severity, derived from the 
health belief model and the theory of protection motivation, have been suggested for social cognition models (Conner \& Norman, 2005).

Many studies have tested the common social cognition models and theories in various domains, including health-related behaviors and consumer health behavior. For meta-analytic reviews of these theories, one can refer to the major works of Albarracin, Johnson, Fishbein, and Muellerleile (2001); Armitage and Conner (2001); and Cooke and French (2008). On the other hand, it is interesting that, from a consumer behavior perspective, social cognition models have also been used as conceptual frameworks to build upon consumer research models of attitude, purchase intention, and purchasing behavior. Sheppard, Hartwick, and Warshaw (1988) and Notani (1998) conducted meta-analyses in the domain of consumer behavior. More specifically, in the domains of pharmaceutical marketing and consumer health behavior, several studies have employed social cognition models (Bowman, Heilman, \& Seetharaman, 2004; Lodorfos, Mulvana, \& Temperley, 2006). Furthermore, the reasoned action model has been successfully used to predict parents' intention and behavior toward using health products for their children, such as using oral rehydration products (Hounsa, Godin, Alihonou, Valois, \& Girard, 1993), vaccination (Askelson et al., 2010), and complementary feeding for children (Hamilton, Daniels, White, Murray, \& Walsh, 2011).

However, to my knowledge, no studies in the domain of consumer health behavior explored intention and behavior of parents to administer OTC pharmaceutical products to their children. The present research proposes a research model based on the social cognition models.

\section{Hypotheses}

In the context of this research, parents' intention to use OTC preventive medications depends on five predictor constructs. In light of the theory of planned behavior, parents' attitude toward the behavior of giving medications to their children depends on the evaluation of the likely consequences of the action. Attitude toward the behavior is conceptualized to predict intention toward the behavior (Ajzen, 1991, 2012). Similarly, in the health belief model, perceived advantage and disadvantage are assumed to predict the likelihood of one's action against the preventive action (Becker et al., 1977). Relying on these arguments, the first antecedent to intention to use OTC preventive medications is parents' perceived benefit of using the medications. It refers to the degree to which parents hold a favorable or unfavorable evaluation or appraisal of using the medications based on advantages and disadvantages. Hypothesis 1 was proposed as follows: 
H.1: Favorable perceived benefit of administering OTC preventive medications to children has a positive effect on parents' intention to use such medications.

The second antecedent to intention to use OTC preventive medications is perceived social pressure. It refers to the extent to which parents perceive social pressure from referent groups to give certain OTC preventive medication to their children. In other words, this antecedent deals with the likely approval or disapproval of a behavior by the subject's reference groups or subjective norm according to reasoned action model (Fishbein \& Ajzen, 2010) in addition to considering cues to actions, which are part of the health belief model (Becker et al., 1977). Perceived social pressure includes two types of norms, namely injunctive norm (subjective norm) and descriptive norm, which is the perception of the importance that other parents also use the medications. Hypothesis 2 was proposed as follows:

H.2: Favorable perceived social pressure regarding the administration of OTC preventive medications to children has a positive effect on parents' intention to use such medications.

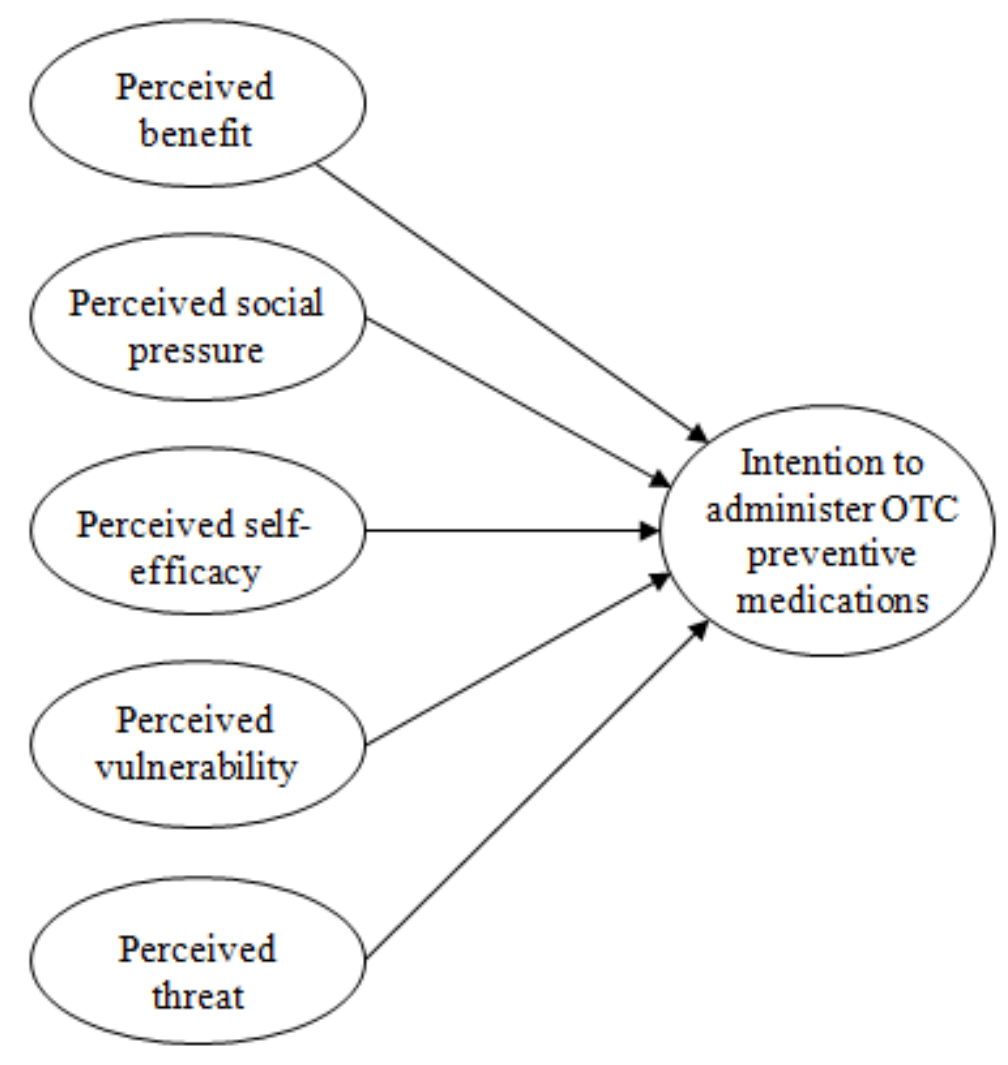

Figure 2 Research Model 
The next antecedent to intention to use OTC preventive medications is perceived self-efficacy. It refers to parents' perceived ease or difficulty in giving OTC preventive medications to their children. Perceived self-efficacy relies on control beliefs about the presence or absence of required resources and opportunities to use the medications. Perceived self-efficacy about the use of the medications also reflects parents' experiences as well as their anticipation about future opportunities and obstacles of using the medications. Perceived self-efficacy includes parents' perceived capability and their own controllability in using the medications (Ajzen, 2012; Fishbein \& Ajzen, 2010). Hypothesis 3 was as follows:

H.3: Favorable perceived self-efficacy of giving OTC preventive medications to their children has a positive effect on parents' intention to use such medications.

The fourth antecedent to intention to use OTC preventive medications is parents' perceived vulnerability of their children to the health problem. It refers to parents' perception of the likelihood that their children will contract a health problem preventable by the preventive medications (Becker et al., 1977; Rogers, 1983). The fifth antecedent to intention to use OTC preventive medications is parents' perceived threat that their children will experience a health problem. It is a multiplicative combination of perceived vulnerability and perceived severity of a particular health problem that can be prevented with the use of medications. Theoretically, it can be assumed that parents are concerned most with the vulnerability to an illness regardless of its severity. On the contrary, parents may worry about the severity of the illness only if they perceive a certain level of vulnerability. It is therefore reasonable to assume that parents' intention to use preventive medications for their children will increase with higher perceived vulnerability and higher interaction between perceived vulnerability and perceived severity. Hypothesis 4 and 5 were as follows:

H.4: Perceived vulnerability of children to experience a health problem has a positive effect on parents' intention to use OTC preventive medications to prevent the occurrence of health problem.

H.5: Perceived threat that children will experience a health problem has a positive effect on parents' intention to give OTC preventive medications to the children.

\section{RESEARCH METHOD}

\section{Qualitative Study}

To build a specific research model and to develop measurement scales, population-specific contents need to be identified so that the scales can capture the dimensions of the constructs under investigation. For these purposes, in-depth 
interviews and an elicitation study were carried out prior to the quantitative survey. Ten mothers who satisfied the inclusion criteria were recruited for in-depth interviews. The mothers were interviewed according to the procedures. The contents of the interviews were audio-taped, transcribed, and analyzed according to procedures developed by Berg (2009). This qualitative study was guided by an eliciting semistructured questionnaire to reveal specific salient beliefs underlying cognitive factors, such as perceived advantage and disadvantage, perceived social pressure, and perceived self-efficacy.

Furthermore, in an elicitation study, 28 mothers completed a questionnaire regarding vitamin supplements. The questions used for the elicitation study were adopted from Fishbein et al. (2001) and Fishbein and Ajzen (2010). The purpose of this analysis was to investigate population-specific themes for the construction of measurement scales. The themes were listed in order from the most frequently mentioned to the least frequently mentioned by mothers, and the most commonly expressed themes and words were used for the measurement scales.

\section{Measurement Scales}

All developed scales were measured on a bipolar 7-point Likert scale according to the findings from the aforementioned qualitative studies. The scales were used to measure the five predicting factors and medicating intention. The development of the measurement scales followed the recommendations from Champion (1984), Fishbein et al. (2001), Ajzen (2006), and Fishbein and Ajzen (2010). These direct measures are assumed to capture all salient beliefs underlying each factor. The measures addressed population-specific contents because they reflect specific health problems and the medications intended for the treatment of the health problems.

The behavior under the investigation was defined in terms of its target, action, context, and time elements (Ajzen, 2006). The behavior was defined as mothers' administration of vitamin supplements to their children. A period of six months was used as a timeframe for accessing medicating intention, which was stated clearly in the questionnaire. The study participants comprised of mothers who have at least one child aged between 2 and 12 years and who live in the urban districts of Ho Chi Minh City. Urban mothers were selected because of the complex meanings of psychological words used in the questionnaire. Children aged between 2 and 12 years were chosen because they are in the phase of physical and intellectual development. Mothers were approached at their children's primary schools for convenient sampling.

The intention to administer vitamin supplements to children within six months was assessed using items recommended by Fishbein and Ajzen (2010). The verbs used 
to express intention of mothers were "to intend," "to be willing to," "to attempt," "to try," and "will." As a result, intention was measured using five items, the scores of which were averaged to calculate a final score. Perceived benefit of using OTC preventive medications was measured directly by attitudinal items comprised of seven pairs of bipolar adjectives reflecting the attitude toward using the preventive medications. These adjectives, such as "bad, good," "harmful, beneficial," "unsafe, safe," "ineffective, effective," "unnecessary, necessary," and "improper, proper," and "not costly, costly," were identified from content analysis of the qualitative studies. The items' scores were averaged to calculate a final score. Perceived social pressure was measured by four items. The high-level referent groups, comprised of "people with specialized knowledge" and "close people I trust," were mentioned to measure the injunctive norm. Furthermore, the descriptive norm was measured using terms like "mothers I admire" and "mothers like me," according to suggestions from Ajzen (2006) and Fishbein and Ajzen (2010). The items' scores were averaged to calculate a final score. Perceived self-efficacy was measured using four items. Two items reflect mothers' perceived capability to use OTC preventive medications, and another two illustrate mothers' controllability when administering OTC preventive medications to their children. The measurement of perceived self-efficacy comprised perceived capabilities of parents, using terminology like "possible," "easy," and "can make choice of medications." The perceived controllability was measured using wording like "decisive," "control," and "active." For direct measures, the following phrases were used to capture perceived capability of performing the behavior: "I am confident that I can," "if I really want, I can," and "Easy-difficult." The following were used to capture a behavior's controllability: "I am active in suing," "I control by myself," and "I completely decide." The measurement items' scores were averaged to calculate a final score.

Perceived vulnerability was assessed by measuring the perceived likelihood of children to contract a health problem within a specified period (Ajzen, 2006). In the context of OTC preventive medications, I need to mention the health problems parents expressed in the interviews. Most health problem themes, specifically the vitamin supplement category, were then converted into negative wording. The item scores were averaged to calculate a final score. Similar to the measures of perceived vulnerability, scales measuring perceived severity quantified the perception of seriousness of the health problems that were of the greatest concern among parents. Perceived severity refers to the perceived harmful consequences of the conditions. The measurement items corresponded to the items of perceived vulnerability. Measurement items' scores were averaged to calculate a final score. 


\section{FINDINGS}

\section{Sample}

A sample of 299 mothers completed the quantitative questionnaire. Most participants (40\%) were between 36 and 40 years old. Most mothers had completed college or higher degrees (57\%), earned less than ten million Vietnamese dongs per month (53\%), and had two children (66\%) with the mean age between 8 and 12 years $(50 \%)$.

\section{Hypothesis Testing}

Exploratory factor analysis was used to assess the unidimensionality and convergent validity of each of the measurement scales (Churchill, 1979). As recommended by Hair, Black, Babin, Anderson, and Tatham (2006), a solid conceptual foundation is required to justify an existing structure of each construct before factor analysis can be carried out. In the research model of the present work, the factors were derived from existing theories and models. These constructs were assumed to have a clear theoretically supported underlying structure. Therefore, exploratory factor analysis in the present research was conducted with items of the individual constructs, though not for all items of all constructs of the research model at one time. Cronbach's alpha was estimated for each measurement scale to assess the reliability. Criteria for this assessment include Cronbach's alpha of at least 0.70 and the item-to-total correlation exceeding 0.50 (Hair et al., 2006). Factor analyses of the items of individual constructs were conducted using a principal component analysis with Varimax rotation using SPSS version 19.0 to check whether the items load on a single factor.

The five items that were supposed to measure medicating intention loaded on a single factor (factor loadings $0.791-0.903$ ), explaining $72.661 \%$ of the total variance with Cronbach's alpha of 0.905 . The six items assumed to measure perceived benefit loaded on a single factor (factor loadings 0.622-0.876), explaining 64.654\% of the total variance with Cronbach's alpha of 0.887 . The four items assumed to measure perceived social pressure loaded on a single factor (factor loadings 0.791-0.828), explaining $63.772 \%$ of the total variance with Cronbach's alpha of 0.810 . The five items assumed to measure perceived self-efficacy loaded on a single factor (factor loadings $0.713-0.855$ ), explaining $62.549 \%$ of the total variance with Cronbach's alpha of 0.849 . The three items assumed to measure each of the two constructs, perceived vulnerability and perceived severity, loaded on single factors (factor loadings $0.823-0.876$ and $0.777-0.829$ ), explaining $73.335 \%$ and $63.703 \%$ of the total variance with Cronbach's alpha of 0.818 and 0.715 , respectively. 
Table 1 Correlations, Mean Scores (M) and Standard Deviations (SD) of Variables

\begin{tabular}{lcclllll}
\hline & MI & BN & SP & SE & VN & SV & PT \\
\hline MI & - & $0.775^{* *}$ & $0.772^{* *}$ & $0.795^{* *}$ & $0.290^{* *}$ & $0.289^{* *}$ & $0.333^{* *}$ \\
BN & & - & $0.681^{* *}$ & $0.674^{* *}$ & $0.296^{* *}$ & $0.333^{* *}$ & $0.354^{* *}$ \\
SP & & & - & $0.674^{* *}$ & $0.328^{* *}$ & $0.248^{* *}$ & $0.339^{* *}$ \\
SE & & & & - & $0.198^{* *}$ & $0.264^{* *}$ & $0.250^{* *}$ \\
VN & & & & & - & $0.228^{* *}$ & $0.917^{* *}$ \\
SV & & & & & & - & $0.535^{* *}$ \\
PT & & & & & & & - \\
M & 4.251 & 4.783 & 4.154 & 4.518 & 2.694 & 4.634 & 12.920 \\
SD & 1.624 & 1.345 & 1.418 & 1.520 & 1.463 & 1.317 & 8.628 \\
\hline
\end{tabular}

Note: $\mathrm{MI}=$ medicating intention, $\mathrm{BN}=$ perceived benefit, $\mathrm{SP}=$ perceived social pressure, $\mathrm{SE}=$ perceived self-efficacy, $\mathrm{VN}=$ perceived vulnerability, $\mathrm{SV}=$ perceived severity, $\mathrm{PT}=$ perceived threat, $\mathrm{M}=$ mean, $\mathrm{SD}=$ standard deviation.

** $\mathrm{p} \leq 0.01$.

According to the results, no further refinement and data reduction is required. Based on the satisfying result from the exploratory factor analyses, the mean scores were computed for items measuring medicating intention, perceived benefit, perceived social pressure, perceived self-efficacy, perceived vulnerability, and perceived severity. Perceived threat was computed by multiplying perceived vulnerability and perceived severity. Correlations among all variables, mean scores, and standard deviations were computed and are presented in Table 1. It is noteworthy that perceived benefit, perceived social pressure, and perceived self-efficacy correlated highly with medicating intention $(r>0.700)$. Perceived vulnerability, perceived severity, and perceived threat were also found to correlate with medicating intention, although the correlation was not high $(\mathrm{r}=0.290-0.333)$.

Multiple regression was performed to assess the prediction power of the entire model and each predictor using SPSS version 19.0. Standardized coefficients were used to identify the relative contribution of individual predictors to the dependent variable because, when the standardized variables are converted into the same units, the magnitude of standardized coefficients indicates the predictors that have the strongest influence. The prediction power of the research model is mainly interpreted by the total percentage of variance explained in medicating intention. Adjusted $\mathrm{R}$ square, instead of $\mathrm{R}$ square, was selected to represent the total percentage of variance 
explained in the dependent variable. The regression result in Table 2 shows that all predictors, except perceived vulnerability and perceived threat, have a positive influence on medicating intention. Perceived self-efficacy was found to be the most influential predictor of medicating intention $(\beta=0.383)$, followed by perceived benefit $(\beta=0.305)$ and perceived social pressure $(\beta=0.296)$. Perceived vulnerability and perceived threat did not significantly predict medicating intention $(\mathrm{p}=0.997$ and $\mathrm{p}=0.677$, respectively). The model can explain $77.5 \%$ of the variance in the medicating intention of vitamin supplements. The multiple regression results support hypotheses 1, 2, and 3 but not hypotheses 4 and 5 .

Table 2 Multiple Regression Predicting Medicating Intention

\begin{tabular}{ccccc}
\hline Variables & Adjusted $\mathrm{R}^{2}\left(\mathrm{R}^{2}\right)$ & $\mathrm{B}$ & Std. Error & Beta \\
\hline & & & & \\
(Constant) & $0.775(0.779)$ & -0.837 & 0.181 & \\
BN & & 0.368 & 0.050 & $0.305^{* * *}$ \\
SP & & 0.339 & 0.048 & $0.296^{* * *}$ \\
SE & & 0.409 & 0.044 & $0.383^{* * *}$ \\
VN & & 0.000 & 0.078 & $0.000^{\text {ns }}$ \\
PT & & 0.006 & 0.013 & $0.030^{\text {ns }}$ \\
\hline
\end{tabular}

Note: $\mathrm{BN}=$ perceived benefit, $\mathrm{SP}=$ social pressure, $\mathrm{SE}=$ self-efficacy, $\mathrm{VN}=$ perceived vulnerability, $\mathrm{PT}=$ perceived threat, $\mathrm{B}=$ unstandardized coefficients, Std. Error $=$ standard error.

${ }^{* * *} p \leq 0.001 .{ }^{n s}=$ not significant.

\section{Moderating Effect of Perceived Vulnerability and Perceived Threat}

Although perceived vulnerability and perceived threat were not found to significantly predict medicating intention $(\mathrm{p} \leq 0.05)$, it is theoretically and managerially relevant to find out how these constructs moderate the relationship between the other individual predictor constructs and medicating intention. To do so, moderated regression was carried out with standardized variables, or z values (Aiken \& West, 1991), which can be computed by SPSS according to the conceptualization of Baron and Kenny (1986). The construction of interaction terms, such as the interaction term of perceived benefit with perceived vulnerability and perceived threat, were also prepared. Medication intention was then regressed on either perceived vulnerability or perceived threat with individual predictor variables and the corresponding interaction term. Multiple regression results showed that both perceived vulnerability and perceived threat moderate only the relationship between perceived benefit and 
medicating intention. Perceived vulnerability and perceived threat did not moderate the relationship between the other predictor variables and medicating intention.

To further understand the nature of the moderating effects of perceived vulnerability and perceived threat on the relationship between perceived benefit and medicating intention, a simple slopes analysis was conducted according to Aiken and West (1991). Slope lines were graphed (see Figure 3). It is interesting to find from the interpretation of the slopes lines that, when perceived vulnerability or perceived threat is low, perceived benefit becomes a stronger predictor of medication intention.
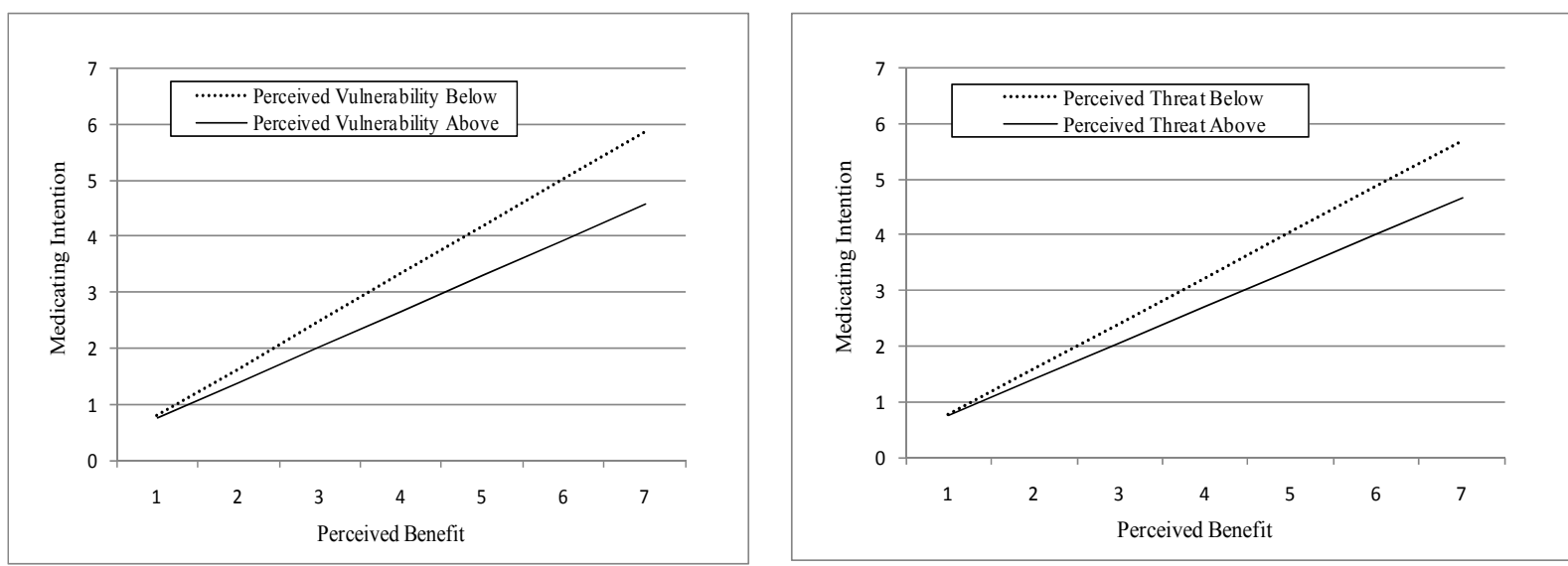

Figure 3 Simple Slope Analysis on Moderating Effect of Perceived Vulnerability (left) and Perceived Threat (right)

\section{DISCUSSION}

The predictive utility of the reasoned action model has been proven across studies carried out in consumer behavior, marketing, and psychology domains (Sheppard et al., 1988). In this research, measurement scales were developed to measure cognitive constructs for predicting medicating intention of OTC preventive pharmaceutical products. The scales measured the constructs of the proposed research model in such a way that the prediction power of the model is satisfactory. The proposed research model could explain $77.5 \%$ of variance in medicating intention. This result is consistent with meta-analyses (Armitage \& Conner, 2001; Cooke \& French, 2008; Notani, 1988).

In a review of research on the health belief model, Janz and Becker (1984) conducted a meta-analysis of 46 studies and found that all four constructssusceptibility, severity, benefits and barriers - were significant predictors of intention in $81 \%, 65 \%, 78 \%$, and $89 \%$ of the studies, respectively. Harrison, Mullen, and Green 
(1992) reviewed 16 studies and found that, although average correlations between the health belief model's components and behavior are statistically significant, the individual constructs could account for just between a half and four percent of the variance in behavior. In the present research, while perceived benefits, measured on bipolar Likert scales to capture both benefits and barriers, significantly and strongly predicted medicating intention, vulnerability and its interaction term with severity did not significantly predict medicating intention. If a higher $p$ value $(p<0.1)$ is accepted, perceived vulnerability and perceived threat can be considered significant predictors of medicating intention but with an incremental marginal percent of variance $(0.4 \%)$. Further empirical studies are needed to reconfirm this phenomenon, at least within the context of OTC preventive pharmaceutical products.

Perceived vulnerability and perceived threat moderated only the relationship between perceived benefit and medicating intention. The simple slopes analysis shows that, when perceived vulnerability or perceived threat is low, perceived benefit becomes stronger in predicting medication intention. The evidence of the moderating effects of these constructs is consistent with the reasoned action model in which Fishbein and Ajzen (2010) modeled "perceived risk" as a background factor. Further, theorists do not have consensus to position perceived vulnerability and perceived threat as immediate antecedents of behavioral intention (Fishbein et al., 2001). On the other hand, regarding the interpretation of the moderating effects revealed in the present research, Ecklund's study (2001) found significant correlations between perceived severity of and perceived susceptibility to the need to visit healthcare professionals rather than self-medication. The explanation of the phenomenon is that, when perceived vulnerability and perceived threat are high, others would not appreciate the benefits of OTC preventive medications but rather rely on doctors' consultation and medication prescriptions. Further studies are needed to provide better understanding of the moderators, such as perceived vulnerability and perceived threat.

\section{CONCLUSION}

\section{Theoretical Implications}

Theoretically, this research aimed to develop and to empirically test a medicating intention model. Such a model has not been intensively tested yet. Furthermore, this research provides evidence for the moderating effects of perceived vulnerability and perceived threat on the relationship between perceived benefit and intention to administer a category of OTC preventive medication. 
Most research work in pharmaceutical marketing has been conducted in Western Europe or North America. Research models applicable in these territories may not be assumed to be equally applicable in all regions of the world; therefore, an Asian context is necessary for new research work. Consequently, this research potentially yields new knowledge of methodologies in terms of measurement instruments (Steenkamp, 2005), which require different development through this research.

\section{Managerial Implications}

Managerially, this research tested the model in a Vietnamese sample living in Vietnam, which is one of the emerging pharmaceutical markets in the Asia-Pacific region (Campbell \& Chui, 2010). The research provides implications regarding the medicating intention of parents to use OTC preventive pharmaceutical products at the category level. It improves the understanding of the relative importance of different factors that explain parents' intention to use commercial OTC preventive medications.

The results of this research provide knowledge for designing more effective integrated marketing programs within the pharmaceutical industry. Such programs should exploit different components relevant to the strategic and tactical implementation of marketing programs using a solid scientific foundation of prediction. Consumer communication campaigns can focus on shaping and changing certain reasoned action factors to influence consumers' intention and behaviors in terms of administering OTC preventive medications to children.

\section{Limitations and Directions for Further Studies}

First, the present research did not include fathers in the quantitative samples of respondents; consequently, the model might not be generalizable to fathers of children. Because fathers and mothers perceive illness prevention and preventive medications differently, the present research could not provide a more comprehensive understanding of overall parents' medicating intention. The interrelationship between fathers and mothers could be even more interesting to both academics and marketers. The present research also has a limitation in generalizing the findings because it is carried out only with vitamin supplements and children from certain age groups. Empirical studies with other preventive medications and other age groups of children are necessary for the generalization of findings. Finally, the present research did not study parents' medicating behaviors, only the intention to medicate. The crosssectional design has a limitation in terms of observing actual behaviors, the relationship between the constructs, and the behavior itself. Further research should 
observe actual behaviors and should test intervention measures to increase the understanding of the intention-behavior relationship.

\section{REFERENCES}

Aiken, L. S., \& West, S. G. (1991). Multiple regression: Testing and interpreting interactions. Thousand Oaks, CA: Sage.

Ajzen, I. (1991). The theory of planned behavior. Organizational Behavior and Human Decision Processes, 50, 179-211. http://dx.doi.org/10.1016/07495978(91)90020-T

Ajzen, I. (2006). Constructing a Theory of Planned Behavior Questionnaire. Retrieved from http://people.umass.edu/aizen/pdf/tpb.measurement.pdf

Ajzen, I. (2012). The theory of planned behavior. In P. A. M. v. Lange, A. W. Kruglanski \& E. T. Higgins (Eds.), Handbook of theories of social psychology (Vol. 1, pp. 438-459). London, UK: Sage Publications.

Albarracin, D., Johnson, B. T., Fishbein, M., \& Muellerleile, P. A. (2001). Theories of reasoned action and planned behavior as models of condom use: A meta-analysis. Psychological Bulletin, 127, 142-161. http://dx.doi.org/10.1037/00332909.127.1.142

Armitage, C. J., \& Conner, M. (2001). Efficacy of the theory of planned behavior: a meta-analytic review. British Journal of Social Psychology, 40, 471-499. http://dx.doi.org/10.1348/014466601164939

Askelson, N. M, Campo, S., Lowe, J. B., Smith, S., Dennis, L. K., \& Andsager, J. (2010). Using the theory of planned behavior to predict mothers' intentions to vaccinate their daughters against HPV. The Journal of School Nursing, 26(3), 194-202. http://dx.doi.org/10.1177/1059840510366022

Baron, R. M., \& Kenny, D. A. (1986). The moderator-mediator variable distinction in social psychological research: Conceptual, strategic, and statistical considerations. Journal of Personality \& Social Psychology, 51, 1173-1182. http://dx.doi.org/10.1037//0022-3514.51.6.1173

Becker, M. H., Haefner, D. P., Kasl, S. V., Kirscht, J. P., Maiman, L. A., \& Rosenstock, I. M. (1977). Selected psychosocial models and correlates of individual health-related behaviors. Medical Care, 15, 27-46. http://dx.doi.org/10.1097/00005650-197705001-00005

Berg, B. L. (2009). Qualitative Research Methods for the Social Sciences. Seventh edition, Allyn \& Bacon. 
Bowman, D., Heilman, C. M., \& Seetharaman, P. B. (2004). Determinants of ProductUse Compliance Behavior. Journal of Marketing Research, 41, 324-338. http://dx.doi.org/10.1509/jmkr.41.3.324.35987

Campbell, D., \& Chui, M. (2010). Pharmerging Shake-Up: New imperatives in a redefined world. IMS Health.

Champion, V. L. (1984). Instrument development for health belief model constructs. Advances in Nursing Science, 6(3), 73-85. http://dx.doi.org/10.1097/00012272198404000-00011

Churchill, G. A. (1979). A paradigm for developing better measures of marketing constructs. Journal of Marketing Research, 16, 64-73. http://dx.doi.org/10.2307/3150876

Clark, D. W., \& MacMahon, B., (1967). Preventive medicine. Boston, MA: Little, Brown \& Co.

Conner, M., \& Norman, P. (2005). Predicting Health Behaviour: a social cognition approach. In M. Conner \& P. Norman (Eds.) Predicting Health Behaviour (2nd ed; pp. 1-27) Buckingham: Open University Press.

Cooke, R., \& French, D. P. (2008). How well do the theory of reasoned action and the theory of planned behavior predict intentions and attendance at screening programmes? A meta-analysis. Psychology and Health, 23(7), 745-765. http://dx.doi.org/10.1080/08870440701544437

Ecklund, C. R. (2001). Over-the-counter medication use in preschool children. Journal of Pediatric Health Care, 15(4), 168-172. http://dx.doi.org/10.1016/S0891-5245(01)52555-9

Fishbein, M., \& Ajzen, I. (1975). Belief, Attitude, Intention, and Behavior. New York: Wiley.

Fishbein, M., \& Ajzen, I. (2010). Predicting and Changing Behavior: The Reasoned Action Approach. New York: Psychology Press.

Fishbein, M., Triandis, H. C., Kanfer, F. H., Becker, M., Middlestadt, S. E., \& Eichler, A. (2001). Factors influencing behavior and behavior change. Handbook of health psychology, Mahwah, NJ: Lawrence Erlbaum, 3-17. http://dx.doi.org/10.1177/01632780122034966

Hair, J. F., Black, W. C., Babin, B. J., Anderson, R. E., \& Tatham, R. L. (2006). Multivariate data analysis (6th edition). New Jersey: Pearson Education.

Hamilton, K., Daniels, L., White, K. M., Murray, N., \& Walsh, A. (2011). Predicting mothers' decisions to introduce complementary feeding at 6 months. An investigation using an extended theory of planned behaviour. Appetite, 56(3), 674-681. http://dx.doi.org/10.1016/j.appet.2011.02.002 
Harrison, J. A., Mullen, P. D., \& Green, L. W. (1992). A meta-analysis of studies of the health belief model with adults. Health Education Research, 7, 107-116. http://dx.doi.org/10.1093/her/7.1.107

Hounsa, A. M., Godin, G., Alihonou, E., Valois, P., \& Girard, J. (1993). An application of Ajzen's theory of planned behaviour to predict mothers' intention to use oral rehydration therapy in a rural area of Benin. Social Science \& Medicine, 37(2), 253-261.

Jamoulle, M., \& Roland, M. (2003). Champs d'action, gestion de l'information et formes de prévention clinique en médecine générale et de famille. Louvain Médical, 122, 358-365.

Janz, N., \& Becker, M. H. (1984). The health belief model: a decade later. Health Education Quarterly, 11, 1-47. http://dx.doi.org/10.1177/109019818401100101

Kuehlein, T., Sghedoni, D., Visentin, D., Gérvas, J., \& Jamoulle, M. (2009). Quaternary prevention: A task of the general practitioner. Report on a workshop held at the 15th Wonca Europe Conference.

Lodorfos, G. N., Mulvana, K. L., \& Temperley, J. (2006). Consumer behaviour: Experience, price, trust and subjective norms in the OTC pharmaceutical market. Innovative Marketing, 2(3), 41-66.

Manchanda, P., Wittink, D. R., Ching, A., Cleanthous, P., Ding, M., Dong, X. J. et al. (2005). Understanding firm, physician and consumer choice behavior in the pharmaceutical industry. Marketing Letters, 16:3(4), 293-308. http://dx.doi.org/10.1007/s11002-005-5893-1

Menon, G., Raghubir, P., \& Agrawal, N. (2008). Health risk perceptions and consumer psychology. In Haugtvedt, C. P., Herr, P. M. \& Cardes, F. R. (Eds.), Handbook of Consumer Psychology (pp. 982-1010). New York: Lawrence Erlbaum Associates. http://dx.doi.org/10.2139/ssrn.945673

Moorman, C., \& Erika, M. (1993). A model of consumers' preventative health behaviors: The role of health motivation and health ability. Journal of Consumer Research, 20, 208-228. http://dx.doi.org/10.1086/209344

Notani, A. S. (1988). Moderators of perceived behavioural control's predictiveness in the theory of planned behaviour: A meta-analysis. Journal of Consumer Psychology, 3, 207-22.

Rogers, R.W. (1975). A protection motivation theory of fear appeals and attitude change. Journal of Psychology, 91, 93-114.

Rogers, R.W. (1983). Cognitive and physiological processes in fear appeals and attitude change: a revised theory of protection motivation. In J.T. Cacioppo and 
R.E. Petty (Eds). Social Psychophysiology: A Source Book. New York: Guilford Press, 153-76.

Sheppard, B. H., Hartwick, J., \& Warshaw, P. R. (1988). The theory of reasoned action: a meta-analysis of past research with recommendations for modifications and future research. Journal of Consumer Research, 15, 325-339.

Steenkamp, J. B. E. M., (2005). Moving out of the U.S. silo: a call to arms for conducting international marketing research. Journal of Marketing, 69, 6-8.

Stremersch, S., \& Van Dyck, W. (2009). Marketing of the life sciences: A new framework and research agenda for a nascent field. Journal of Marketing, 73, 430. http://dx.doi.org/10.1509/jmkg.73.4.4 